\title{
Anesthesia in patients of aromatic L-amino acid decarboxylase (AADC) deficiency for MRI scan and stereotactic surgery
}

\author{
Li Y.-T. ${ }^{1}$, Fan S.-Z. ${ }^{1}$, Lee N.-C. ${ }^{2}$, Shih P.-Y. ${ }^{1}$ \\ ${ }^{1}$ National Taiwan University Hospital, Dept of Anaesthesiology, Taipei, Taiwan \\ ${ }^{2}$ National Taiwan University Hospital, Dept of Pediatrics and Medical Genetics, Taipei, Taiwan
}

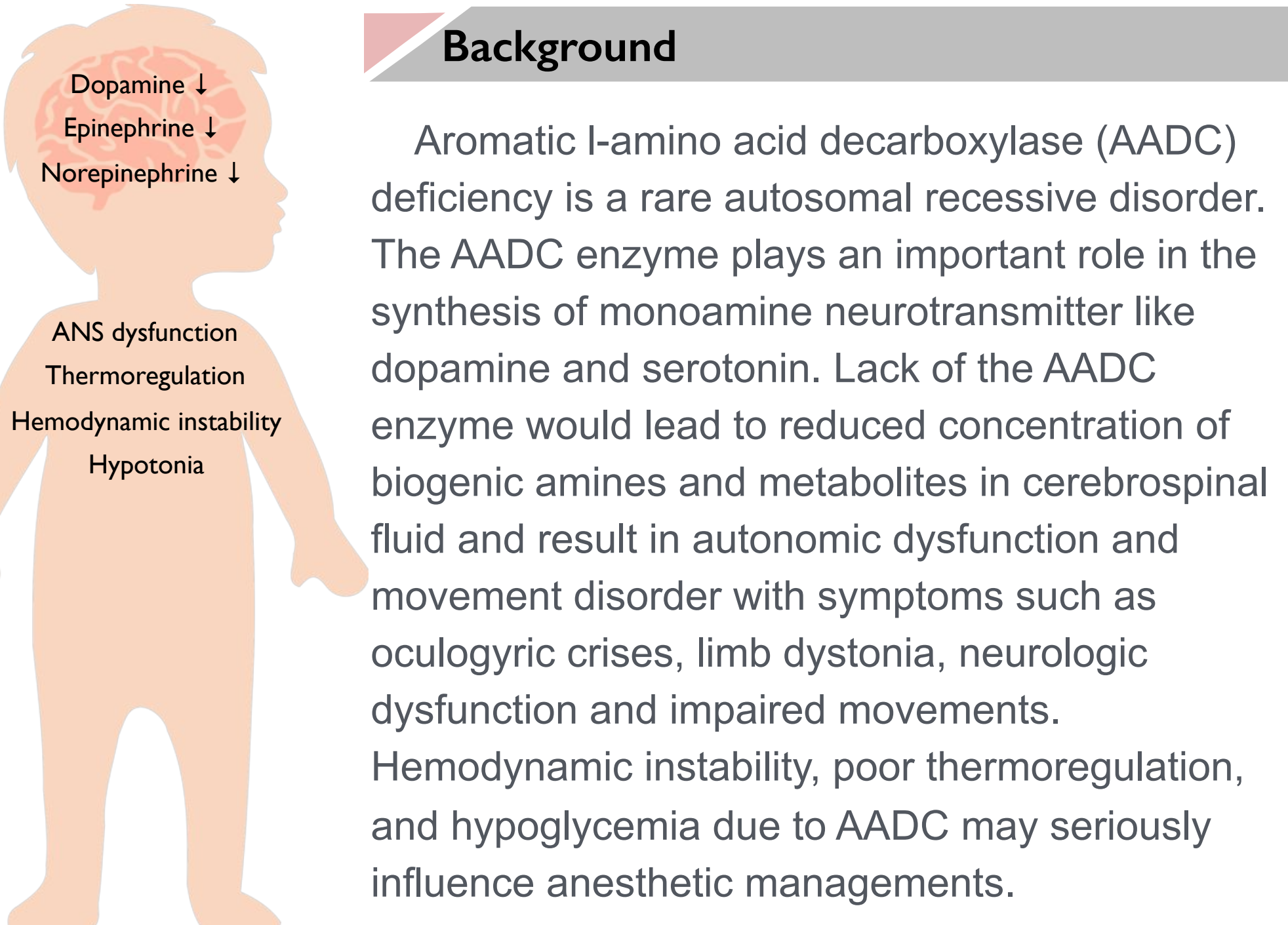

\section{Material \& Methods}

Aromatic l-amino acid decarboxylase (AADC) deficiency is a rare autosomal recessive disorder The AADC enzyme plays an important role in the synthesis of monoamine neurotransmitter like dopamine and serotonin. Lack of the AADC enzyme would lead to reduced concentration of biogenic amines and metabolites in cerebrospinal fluid and result in autonomic dysfunction and movement disorder with symptoms such as oculogyric crises, limb dystonia, neurologic and hypoglycemia due to AADC may seriously

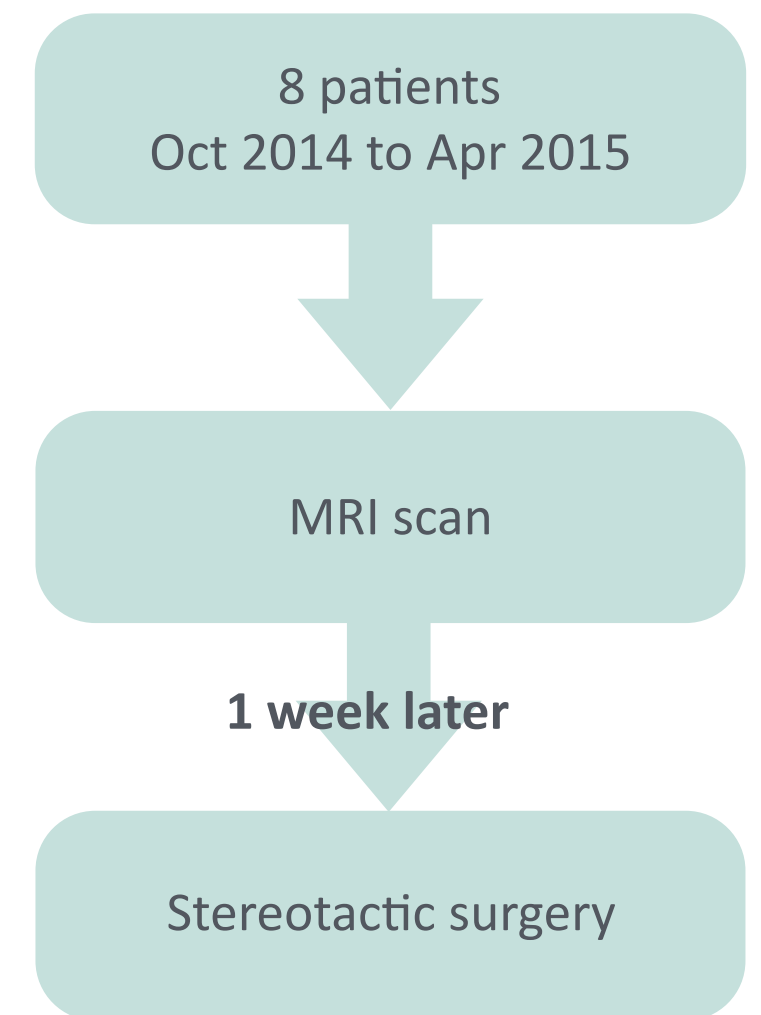

Inclusion criteria:

1. Definite diagnosis of AADC deficiency with the CSF study

2. Older than 24 months, or skull bones suitable for stereotactic surgery

Exclusion criteria:

1. Patient condition not suitable for surgery or anesthesia

\section{Results}

\section{Table 1. patients' demographic data}

\begin{tabular}{cccccccccc} 
patient & age & sex & BH & BW & $\begin{array}{c}\text { MRI duration } \\
(\text { min) }\end{array}$ & $\begin{array}{c}\text { MRI } \\
\text { ICU stay }\end{array}$ & $\begin{array}{c}\text { OP duration } \\
\text { (min) }\end{array}$ & $\begin{array}{c}\text { OP } \\
\text { ICU stay }\end{array}$ \\
\hline 1 & $6 y 2 m$ & F & 97 & 11.0 & 105 & 1 & 488 & 1 \\
2 & $7 y 8 m$ & M & 124 & 20.2 & 75 & 1 & 689 & 2 \\
3 & $8 y$ & F & 126 & 20.5 & 125 & 0.5 & 470 & 6 \\
4 & $2 y 5 m$ & M & 84 & 10.1 & 95 & 3 & 472 & 3 \\
5 & $2 y 8 m$ & M & 88 & 10.0 & 90 & 0 & 518 & 1 \\
6 & $6 y 7 m$ & F & 120 & 17.0 & 70 & 1 & 524 & 3 \\
7 & $2 y 7 m$ & M & 95 & 10.0 & 95 & 1 & 475 & 1 \\
8 & $2 y 10 m$ & F & 91 & 11.0 & 90 & 1 & 530 & 2
\end{tabular}

\begin{tabular}{c|ccc|cc|ccc} 
Table 2. Anesthetic medication during lumbar puncture and MRI scan \\
patient & \multicolumn{3}{|c|}{ Induction } & \multicolumn{3}{c}{ Maintenance } & \multicolumn{3}{c}{$\begin{array}{c}\text { Extubation } \\
\text { citosol }\end{array}$} & atropine & Cistracurium & Cistracurium Ephedrine & Atropine & Neostigmine aminophylline \\
\hline 1 & 50 & 0.2 & 2 & 0 & 0 & 0 & 0 & 0 \\
2 & 75 & 0.2 & 3 & 2 & 0 & 0 & 0 & 0 \\
3 & 100 & 0.5 & 4 & 0 & 0 & 0.4 & 1 & 75 \\
4 & 38 & 0.1 & 3 & 0 & 4 & 0 & 0 & 0 \\
5 & 25 & 0.2 & 2 & 0 & 0 & 0.2 & 0.5 & 0 \\
6 & 75 & 0.2 & 3 & 1 & 0 & 0.4 & 0.8 & 0 \\
7 & 37.5 & 0.3 & 2 & 0 & 0 & 0.2 & 0.5 & 0 \\
8 & 25 & 0.3 & 1 & 0 & 0 & 0.3 & 0.5 & 0 \\
\hline
\end{tabular}

Table 1.

BH: body height, BW: body weight, OP:stereotactic surgery

Table 2.

All the units of doses are milligram(mg). Patient 1,2,4 were transferred to the ICU with endotracheal tube. Patient 4 was under severe bronchitis.

Table 3.

All the units of doses without mentioned are milligram(mg). All the patients were transferred to ICU with endotracheal tube.

\section{Discussion and Conclusion}

Due to reduced concentration of catecholamine and intact parasympathetic activity, anesthetic management in AADC deficiency patients is challenging. In our case series, hemodynamics of AADC deficiency patients were stable during general anesthesia for minor procedure such as MRI scan. In major surgeries with long surgical duration, inotropic or vasoactive support might be necessary. Our study showed that general anesthesia can be conducted safely in AADC deficiency patients with careful monitoring. 